\section{Conhecimento e uso de plantas nativas entre os xavante de Pimentel Barbosa, MT $^{*}$ Knowledge and use of native plants between xavante of Pimentel Barbosa land, MT}

\author{
Rafael Navas** \\ Maria Elisa de Paula Eduardo Garavello***
}

\begin{abstract}
Resumo: O uso de plantas nativas sempre esteve presente na alimentação Xavante, junto com a caça. A agricultura possuía importância secundária para o grupo e, após o fim da mobilidade espacial pelo território, essa atividade ganhou importância para obtenção de alimentos, incentivada pelas políticas da Fundação Nacional do Índio, com aquisição de máquinas agrícolas. Nesse contexto, o objetivo deste trabalho foi avaliar o conhecimento e uso de plantas nativas pelos Xavante da Terra Indígena Pimentel Barbosa, Mato Grosso e o impacto da agricultura na atividade. $\mathrm{O}$ trabalho foi realizado entre 2006 e 2010, por meio de técnicas qualitativas, com entrevistas e observação participante. Observou-se aproximadamente 60 espécies nativas de uso na alimentação, porém, com o incremento da agricultura mecanizada e o cultivo nos quintais, a coleta foi sendo reduzida, com aumento no consumo de arroz.
\end{abstract}

Palavras-chave: Jê; Etnoecologia; cerrado.

Abstract: The use of native plants always been present in Xavante's food habits, along with hunting. The agriculture had secondary importance to the group and after the end of spatial mobility throughout the territory, this activity has gained importance for obtaining food, encouraged by the policies of the Fundação Nacional do Índio, with the acquisition of agricultural machinery. In this context, the objective of this study was to evaluate the knowledge and use of native plants by Xavante of Terra Indígena Pimentel Barbosa, Mato Grosso and the impact of agriculture in the activity. The study was conducted between 2006 and 2010, using qualitative techniques, with interviews and participant observation. There was about 60 native species of use in food, but with the increase of mechanized farming and farming in backyards, the collection was being reduced with increased consumption of rice.

Key words: Jê; Ethnoecology; cerrado.
* Parte da Dissertação de Mestrado apresentada ao Programa de Pós-graduação em Ecologia Aplicada - ESALQ/ USP, Piracicaba, SP.

** Doutor em Ecologia Aplicada pela Universidade de São Paulo, Eng. Agrônomo. E-mail: navas_ri@yahoo.com.br

*** Professora Associada da Escola Superior de Agricultura Luiz de Queiroz, Universidade de São Paulo. E-mail: mepegara@usp.br 


\section{Introdução}

No início do século XVIII, os xavante junto com os xerente habitavam a bacia do Rio Tocantins e formavam um só povo, pertencente ao grupo etnolinguístico Acuen, da família Jê. Nessa região, ocupavam um amplo território. Com a descoberta de ouro na região ocupada por esse povo, atuais Estados de Goiás e Tocantins, e a chegada de mineradores, bandeirantes, colonos e missionários, houve pressão sobre esse povo, ocasionando diversos conflitos. Alguns nativos reagiram com ataques e guerras, outros aceitaram a aproximação ou migraram em busca de novos territórios (MAYBURY-LEWIS, 1984).

Na segunda metade do século XVIII, em busca de refúgio, alguns grupos xavante estiveram assentados em aldeamentos do governo, mas tiveram os efeitos das epidemias. Diante dos problemas de saúde nesses locais, os indígenas optaram pela saída dos aldeamentos e, no final do século XVIII, os xavante cruzaram o Rio Araguaia e se estabeleceram na região da Serra do Roncador, atual estado de Mato Grosso. Durante o século XIX e a primeira metade do XX, o grupo sofreu divisões, e realizaram novas migrações para oeste, nas margens do Rio das Mortes, Suiá-Missu e Kuluene. Até a terceira década do século $X X$, todos eles viveram relativamente livres do contato da sociedade não indígena. Após esse período, a política adotada pelo governo, através da conhecida "Marcha para o Oeste", empreendeu os primeiros esforços para colonizar a região, incentivado em promover seu povoamento e a crescente preocupação com a ocupação das fronteiras. Nessa época, a maior parte dos grupos xavante estabeleceu contato pacífico com representantes da sociedade nacional, esgotados por doenças, fome e conflitos. Alguns grupos buscaram refúgio nos postos do Serviço de Proteção ao Índio (SPI $)^{1}$ ou em missões religiosas. $\mathrm{O}$ último grupo a aceitar o contato permanente foi o de Pimentel Barbosa, ocorrido em 1946 (MENEZES, 1982).

À medida que os xavantes cederam à pressão da expansão nacional, os territórios que ocupavam tornavam-se acessíveis aos propósitos do governo. Assim, conseguiu-se implantar o modelo econômico capitalista no setor rural, através da política adotada no período pós-64, ao mesmo tempo em que se realizaram projetos fundiários, alguns em áreas tradicionalmente ocupadas pelos indígenas (MENEZES, 1982).

Com a adoção do novo modelo agropecuário, extensas áreas de cerrado foram desmatadas, principalmente para o cultivo de arroz e criação de gado.

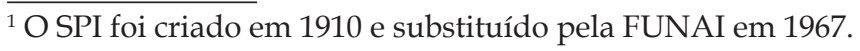


No final da década de 1970 e início de 1980, os xavantes procederam a intensas lutas, visando à recuperação de territórios tradicionalmente ocupados, principalmente aqueles entre aqueles que haviam se refugiado em missões ou postos do SPI. Diante destes conflitos, os xavantes pressionavam a FUNAI e, com os problemas alimentares nas aldeias, principalmente com escassez de caça, o governo reconheceu a necessidade de realizar um projeto para os xavantes, o qual estaria alinhado ao modelo de modernização da região, ao mesmo tempo em que solucionaria os problemas enfrentados. Essa modernização deveria ocorrer também às áreas indígenas, atrelando os índios ao sistema econômico, transformando-os em produtores comerciais. Esta era a política de integração definida pelo governo, em que o índio era reconhecido como sujeito transitório, ou seja, estava sendo preparado para ingressar na "civilização". Essa política apontava para o fim da diversidade étnica e cultural, pois reconhecia essa diversidade apenas como um estágio de desenvolvimento, que se concluiria com a incorporação do índio à sociedade nacional. A política de integração fundava-se na crença de que a civilização ocidental representava o estágio mais avançado, além do que, não se reconhecia o caráter coletivo dessas populações. Por isso, o SPI desenvolvia uma política que propunha dar aos índios condições de evoluir lentamente, até integrarem-se totalmente à sociedade (FUNAI, s.d.). Assim, o órgão demarcava as Terras Indígenas, prestava atendimento de saúde, ensinava técnicas de cultivo e proporcionava educação formal. No final de 1981, seis Terras Xavantes haviam sido demarcadas: Areões, Pimentel Barbosa, São Marcos, Sangradouro, Marechal Rondon e Parabubure.

Com essa submissão dos indígenas ao SPI, o órgão tentou incentivá-los à prática da agricultura, pois para este, os xavantes possuíam um vasto território, que economicamente estava sendo pouco utilizado com o modo de vida tradicional, baseado na realização de excursões de caça e coleta. Essa mesma área poderia sustentar um número bem maior de agricultores, principalmente em uma região que estava sendo aberta à colonização e a atividades produtivas. Para o órgão, incorporando a agricultura como fonte importante de obtenção de alimentos, os xavantes poderiam se adaptar aos poucos à redução de seu território. Além disso, os funcionários do SPI teriam facilidade para administrar os indígenas (MAYBURY-LEWIS, 1984).

Mesmo com esse incentivo, os xavantes ainda realizavam excursões de caça e coleta, em que os índios percorriam o território durante meses, até voltarem para aldeia base, quando se dedicavam à colheita dos produtos que eram cultivados no início da estação das chuvas, e realizavam alguns rituais. De acordo com Silva (1983), os xavantes de Pimentel Barbosa realizaram essas 
excursões até o início da década de 1980. Porém, com o contato permanente e a fragmentação dos territórios, a realização das excursões tornou-se cada vez mais difícil. Com a modernização da agropecuária, a paisagem do entorno de suas Terras foi alterada, e as fontes de alimentos tradicionais reduzidas, principalmente a caça.

Silva (1983), em trabalho com os xavantes na década de 1980, destacou que eles estavam se tornando agricultores, e esse evento poderia fazer com que gastassem mais tempo com essa atividade e menos tempo teriam para a vida social. Da mesma forma, para Sahlins (1978), em sociedades de agricultores, maior tempo é gasto para as atividades produtivas em comparação com sociedades de caçadores-coletores.

Atualmente os xavantes somam 13.000 pessoas, distribuídas em onze Terras Indígenas, geograficamente descontínuas. Apresentam elevadas taxas de natalidade e crescimento populacional desde a década de 1960. Porém a mortalidade infantil é relativamente alta. Dados indicam que $14 \%$ das crianças xavantes não sobrevivem até os dez anos de idade. As causas de morte são resultados de precárias condições sanitárias e contaminação da água. Doenças gastrointestinais e infecções respiratórias são as principais causas das mortes. Esses problemas resultam, em parte, da mudança do padrão de vida com mobilidade espacial pelo sedentarismo (ISA, s.d.).

O sedentarismo, a carência de caça e de outras fontes de proteína, assim como os projetos desenvolvimentistas da FUNAI resultaram em profundas mudanças em sua dieta, que têm levado à desnutrição e a problemas de saúde, como a anemia.

Assim, o objetivo deste trabalho foi realizar o levantamento das espécies nativas do cerrado de uso entre os xavantes e relacionar o aumento da atividade agrícola com a redução na coleta e consumo de frutos.

\section{Metodologia}

A Terra Indígena Pimentel Barbosa $\left(14^{\circ} 41^{\prime} \mathrm{S}\right.$ e 52 $\left.20^{\prime} \mathrm{W}\right)$ possui área de 328.966 hectares e localiza-se nos municípios de Canarana e Ribeirão Cascalheira, no estado de Mato Grosso. Essa TI foi homologada em 1986, e a população atual é de aproximadamente 1.800 pessoas, distribuída em oito aldeias.

Entre essas aldeias, a Wedérã foi o local deste estudo, sendo criada em 1997, com população de 57 pessoas, distribuídas em sete casas. Nessa aldeia, há quatro pessoas da geração anterior ao contato com o não-índio. 
Em todas as viagens para coleta de dados, foram usadas técnicas qualitativas, como as de observação participante, em que o pesquisador participa da rotina e atividades dos pesquisados; entrevistas parcialmente estruturadas, em que alguns tópicos são fixados e outros redefinidos conforme o andamento da entrevista; entrevistas não estruturadas coletivas, em que há um diálogo livre entre pesquisador e informantes; desenhos (VIERTLER, 1988) e conversas informais.

A coleta de dados foi realizada entre os anos de 2006 a 2010.

\section{Resultados e discussão}

\subsection{As plantas nativas e a atividade de coleta}

A subsistência xavante tinha como base as atividades de caça, a coleta de vegetais, a agricultura e a pesca, sendo as duas últimas consideradas de importância secundária (MAYBURY-LEWIS, 1984). Essas diferentes atividades eram condicionadas pela estação, e sua importância variava conforme o período do ano, e harmonizavam-se garantindo uma alimentação equilibrada e completa.

A atividade de coleta constituía-se uma atividade feminina, sendo realizada pelas mulheres de um mesmo grupo familiar e, também, junto com outras mulheres da aldeia, representando uma das poucas oportunidades de relacionamento social fora da casa (MAYBURY-LEWIS, 1984). Badinter (1986) relatou essa divisão do trabalho como sendo evidente em todas as sociedades. Segundo a autora, em sociedades de caçadores-coletores, a divisão do trabalho na obtenção do alimento fazia com que homens e mulheres traçassem trajetórias diferentes, dividindo o território de maneira que a mulher ficava em um espaço circunscrito, enquanto o homem percorria um campo mais vasto.

Durante o trabalho de campo, verificamos o conhecimento pela população da aldeia Wedérã de diversas espécies vegetais de uso na alimentação, e estas estão listadas na Tabela 1, com o tipo de vegetação que ocorre e a forma de consumo. 


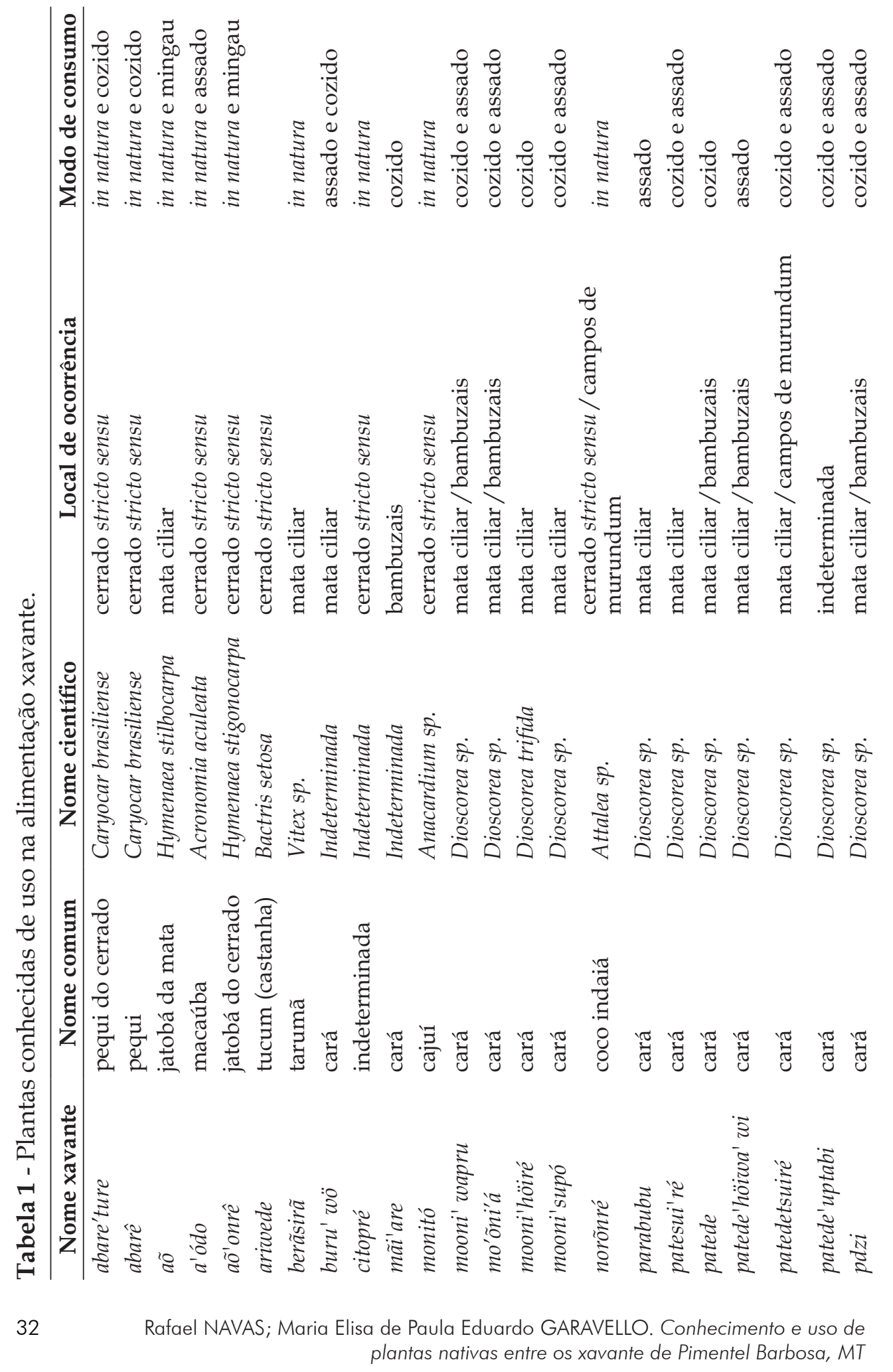




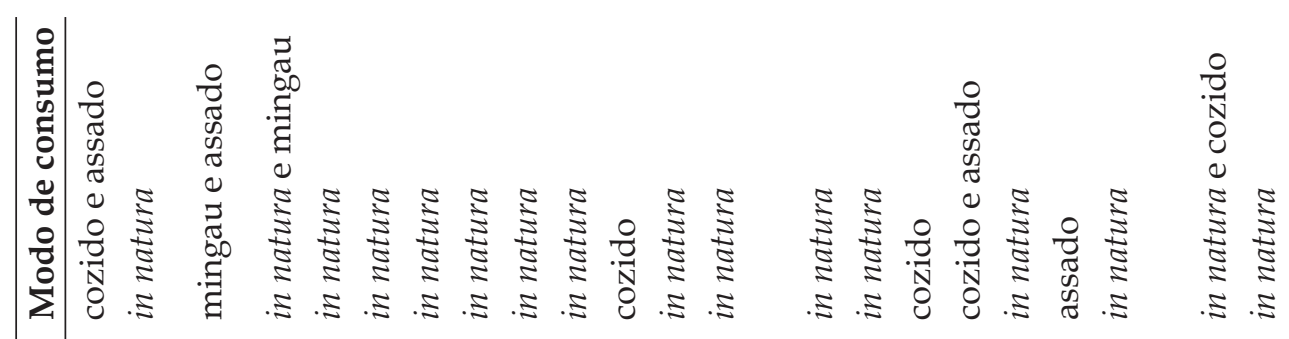

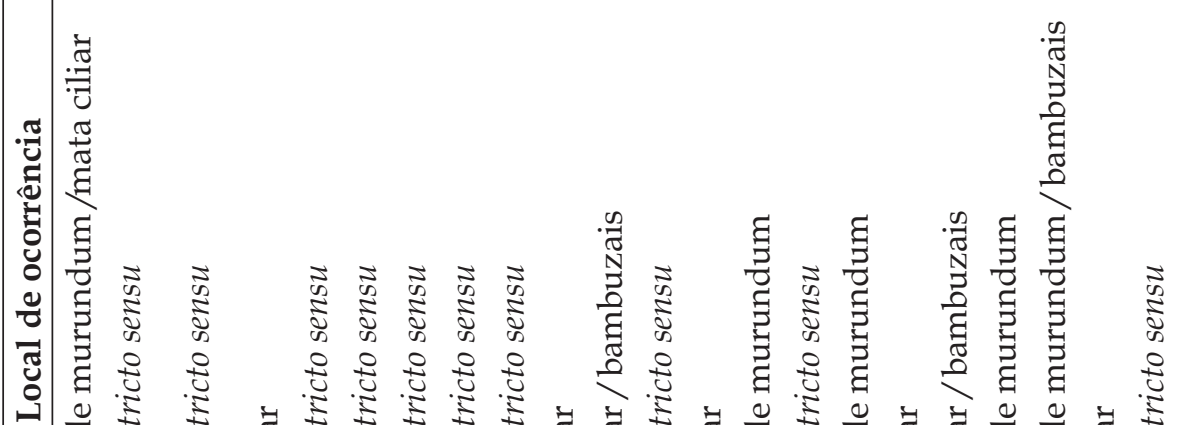

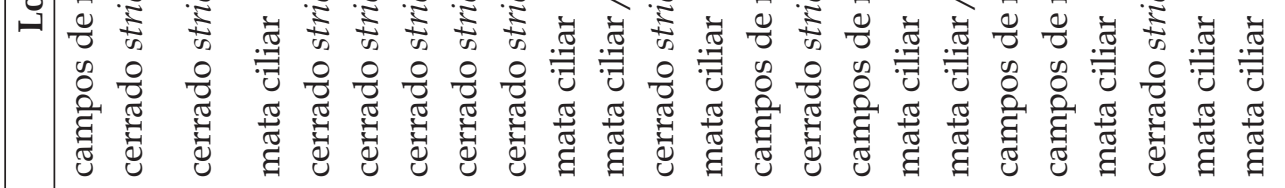

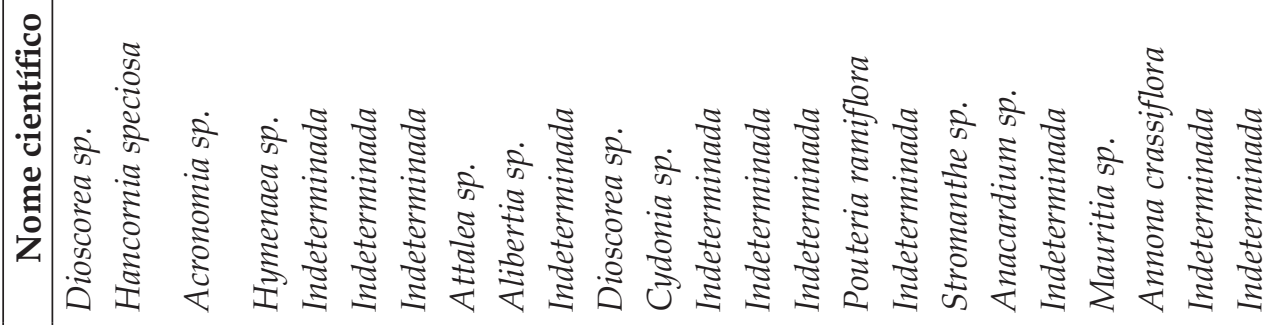

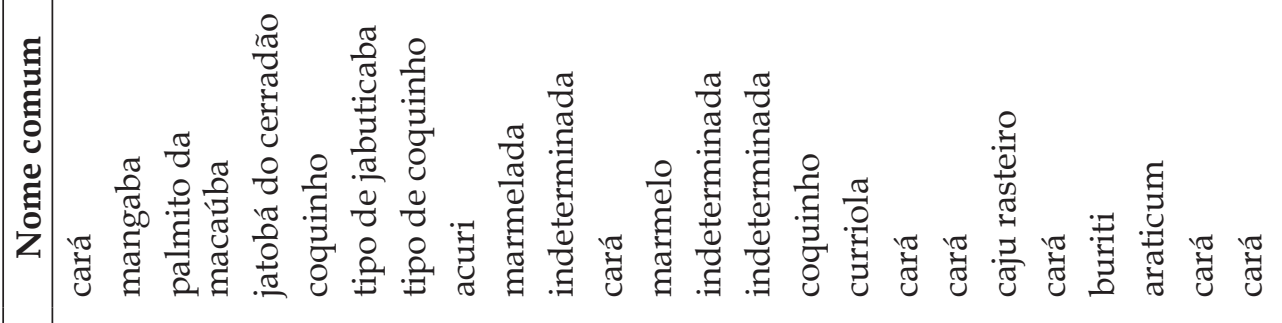

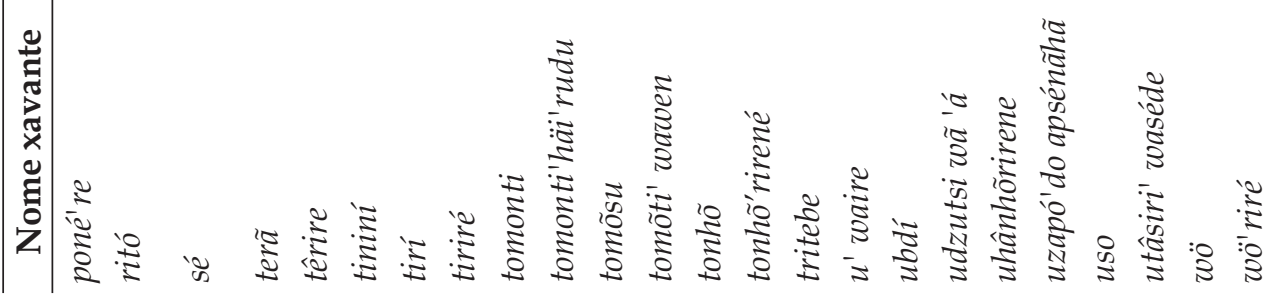




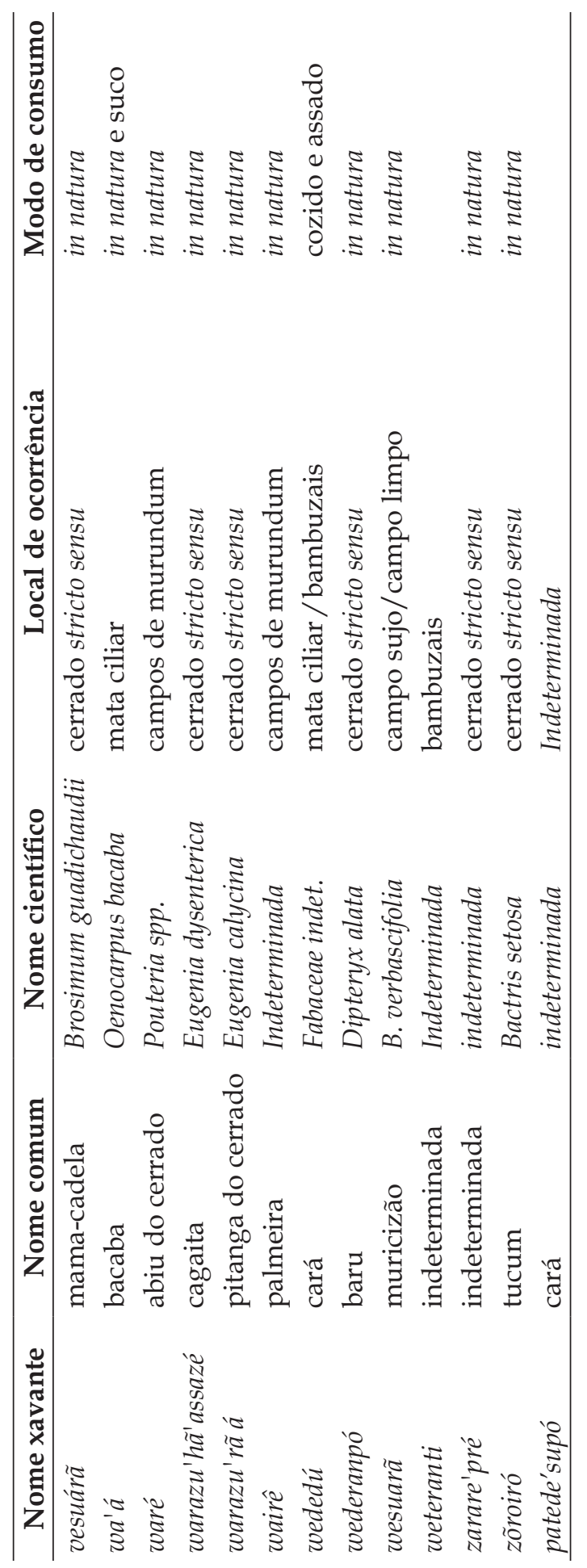
plantas nativas entre os xavante de Pimentel Barbosa, MT 
Com relação aos locais de ocorrência das espécies, o tipo de vegetação correspondente ao cerrado stricto sensu ( $A m^{\prime}$ 'hü), é o local com maior frequência de frutos. Os carás ocorrem com mais frequência em matas ciliares $\left(M a^{\prime} r \tilde{a}\right)$. A vegetação tipo $A^{\prime} p \hat{e}$ corresponde aos campos de murundum, e Sada'rã ao campo limpo, Buru'rã ao campo sujo e Umratã'nã são os locais em que ocorrem os bambuzais. A classificação da vegetação não se limita àquelas citadas neste trabalho: o que foi relatad o refere-se aos locais visitados pelo pesquisador com os indígenas nas atividades de campo.

Há carás que ocorrem em regiões específicas, e alguns, como Moo'ni'á e Mooni'wapru, localizam-se longe das áreas da aldeia, e outros, como Mooni'höi'ré, localizam-se em áreas próximas. Essa especificidade de ocorrência das plantas e a fixação das aldeias contribuem também para que os jovens não conheçam tantas espécies de plantas, em especial pelo estilo de vida com pouca mobilidade pelo território. Alguns carás relatados pelos xavantes, também foram observados por Maybury-Lewis (1984, p. 88).

Na prática de coleta, as mulheres saem caminhando pelo cerrado com cestos, coletando os frutos encontrados. Saem nas primeiras horas do dia para realizarem essa atividade, devido a temperaturas elevadas da região. Quando vão para a roça, aproveitam para coletar frutos que encontram, como o buriti, pois as roças são em áreas de mata ciliar e nestas encontram-se muitas plantas dessa espécie, além de frutos de palmeiras nativas do cerrado, presentes nas roças-de-toco.

Tal conhecimento, entretanto, não é garantia de uso na alimentação. Pôde ser verificado que atualmente a coleta não tem a mesma importância como base alimentar. As mulheres não a realizam com frequência. Apenas em uma casa houve o relato dessa prática rotineiramente realizada pelas mulheres desse grupo familiar. Já as demais a realizam apenas quando não há outra fonte de alimento.

Leeuwenberg e Salimon (1999), em trabalho com os xavantes, observou que as mulheres não estavam realizando a atividade de coleta com frequência, e esse mesmo fato foi descrito por Leite (2007) entre os Wari, embora esse povo possuísse fonte desse alimento em seu território.

Em contexto diferente, Woortmann (1999) observou, entre comunidades pesqueiras, que, com a mudança na paisagem, as mulheres deixaram de praticar a coleta de plantas nativas e, com isso, a concepção da comunidade em relação a elas foi alterada.

Badinter (1986) citou que, entre sociedades de caçadores-coletores, a coleta era uma atividade perigosa e exigia muita energia e inteligência. As 
mulheres tinham que realizá-la com rapidez e eficiência, buscando plantas nutritivas, ao mesmo tempo em que estavam atentas aos perigos e aos filhos pequenos que as acompanham.

Quando é época de frutificação de determinadas espécies, como pequi e baru, os membros da aldeia vão de carro até os locais conhecidos para realizarem a coleta destes, pois são produtos apreciados na dieta, e as plantas produzem grande quantidade de frutos. Assim, a coleta realizada por todas as mulheres, só é praticada nessa ocasião. O espaço explorado por elas altera-se dessa forma, pois, indo de carro, vão apenas para os locais conhecidos de determinadas espécies, principalmente aquelas citadas acima. $\mathrm{O}$ uso do território limita-se aos locais próximos a estradas. De acordo com informação dada, por estar em uma área nova no território, já que a aldeia foi criada em 1997, a comunidade não conhece muitos locais com espécies frutíferas, sendo que, por esse motivo, o conhecimento também deixa de ser transmitido para as mais jovens.

Os homens também conhecem as épocas de frutificação das espécies, sendo comum quando caçam e pescam, alimentarem-se de frutos encontrados no caminho.

Na classificação das plantas de uso na alimentação, nota-se que existem diferentes denominações para a mesma espécie vegetal, dependendo da parte consumida. Isto evidencia como o conhecimento e a classificação das plantas que a comunidade faz se relacionam às funções práticas do cotidiano.

Os conhecimentos que as populações indígenas possuem são produzidos a partir de atividades e práticas coletivamente desenvolvidas nos ambientes ocupados e explorados, correspondendo ao que a Convenção sobre a Diversidade Biológica designa de "conhecimentos, inovações e práticas das comunidades locais e populações indígenas com estilos de vida tradicionais". São essas práticas, inovações e conhecimentos que conservam a diversidade biológica dos ecossistemas (ALTIERI; NICHOLLS, 2000). Barbosa e Craveiro (2004) descreveram entre os xavante que, durante as realizações do zöomo'ri (caçadas familiares), “os jovens, homens e mulheres recebiam ensinamentos sobre os detalhes de caça, pesca e coleta de materiais naturais e medicinais".

Os processos, práticas e atividades tradicionais dos povos indígenas que geram a produção de conhecimentos e inovações relacionados a espécies e ecossistemas - dependem de um modo de vida estreitamente relacionado à natureza. A continuidade da produção desses conhecimentos depende de condições que assegurem a sobrevivência física e cultural desses povos. 
Devido à redução do território dos xavantes a partir da criação da TI Pimentel Barbosa, aos conflitos pela ocupação das terras indígenas ${ }^{2}$, ao fim da mobilidade pelo território a partir das décadas de 1970 e 1980 e aos problemas de alimentação surgidos, a FUNAI implementou projetos de cultivo mecanizado de arroz nas aldeias da região Central do Brasil. Tais projetos visavam solucionar os problemas advindos da redução dos territórios indígenas, agravados pelo desmatamento das áreas do entorno e pela ocupação de suas terras, sendo que o excedente de produção seria comercializado. Esse projeto teve duração até o fim da década de 1980, provocando alterações nos padrões de subsistência das populações indígenas dessa região, principalmente pela substituição dos produtos tradicionais, como o milho, pelo arroz, levando à perda de sementes tradicionais. Assim, o arroz passou a ser base da alimentação xavante, fato que permanece nos dias atuais.

Sem a solução dos problemas de alimentação nas aldeias xavantes de Pimentel Barbosa, uma solução pensada pelos indígenas foi pedir o aumento do território para ter maior acesso a fontes de alimentos tradicionais. Com esse aumento, as áreas contíguas seriam desapropriadas. Assim uma Associação da região, formada pelos proprietários do entorno, propôs a realização de um novo projeto de cultivo mecanizado de arroz em conjunto com os indígenas para estes não pedirem o aumento da TI, considerando que esse aumento do território não supriria a necessidade de alimentos por essas comunidades. A duração desse projeto foi prevista para os anos de 2004 a 2010, tendo apoio da FUNAI e da Prefeitura Municipal de Canarana, MT.

A área total de cultivo desse projeto foi de 90 hectares, dividida entre as seis aldeias existentes nessa TI. A área de plantio para cada aldeia era obtida através de cálculos da relação entre a área total a ser plantada (90 ha) e a população de cada aldeia. A aldeia Wede'rã possuía área de plantio de seis hectares, com colheita no último plantio de 280 sacos de arroz. A lavoura pertencente à aldeia Wede'rã foi implantada em área aberta em anos anteriores. A área de plantio foi escolhida pelos membros da comunidade. O sistema de produção foi convencional, utilizando tratores e grade aradora das próprias aldeias. Utilizou-se tratamento das sementes com inseticida e adubação química. Nas etapas de limpeza e preparo do solo para plantio, essas operações eram realizadas por funcionários da prefeitura, com máquinas agrícolas. A capina das lavouras foi realizada pela comunidade das aldeias. A colheita foi

\footnotetext{
${ }^{2}$ A TI Pimentel Barbosa foi homologada apenas em 1986, havendo muitos conflitos entre índios e fazendeiros do entorno, devido à ocupação de suas terras e redução do território. Ainda hoje se observa no território áreas de ocupação de fazendas da década de 80, com presença de currais e construções.
} 
terceirizada, com custo de $\mathrm{R} \$ 7.500,00$ para todas as aldeias, sendo parte deste valor pago pela FUNAI em espécie e uma parte paga em produto colhido. Nas etapas de colheita, a comunidade foi para a lavoura ajudar a ensacar o arroz colhido mecanicamente. A técnica responsável relatou que, no período de colheita, mulheres e crianças percorreram a área após a passagem da colhedora recolhendo cachos de arroz caídos no chão. Para a responsável, esse fato confirmou o interesse da comunidade pelo projeto.

Em 2008, durante nosso trabalho de campo, os membros da aldeia informaram que o projeto da Associação havia terminado devido aos altos custos dos insumos utilizados no cultivo.

3.2 Os impactos da agricultura e da implantação dos quintais

Atualmente existe maior importância da agricultura para a obtenção de alimentos entre os xavantes da aldeia $W e d e^{\prime} r \tilde{a}$, quando no passado essa atividade possuía importância secundária como forma de obter alimentos.

Como entre os bororos, também do grupo Jê, após o contato, a atividade agrícola foi intensificada, com introdução de novos cultivos e técnicas (SERPA, 2001). Os produtos cultivados entre os xavantes eram de ciclo curto, o que favorecia seu cultivo esporádico. Tratava-se de espécies apropriadas, pois dedicavam pouco tempo para essa atividade (MAYBURY-LEWIS, 1984). Os homens mais idosos da aldeia relataram que, quando colhiam os produtos da agricultura, realizavam alguns rituais, como nominação das mulheres, dança e corrida de toras e era a época em que as famílias se encontravam na aldeia base, depois de terem realizado as expedições familiares de caça e coleta.

A partir da fixação das aldeias, os cultivos agrícolas foram também incrementados nos quintais, sendo de cuidado e uso do grupo doméstico. As Tabelas 2, 3 e 4 mostram a evolução dos cultivos nessas áreas entre os anos de 2008 e 2010. Nos dois primeiros anos, o incremento no número de espécies pode ser atribuído à ação do projeto Nutrição, da ONG Nossa Tribo, que implantou diversas espécies frutíferas nativas e exóticas e, também, ao fato de que não houve roças em 2008, todos os cultivos ocorreram nos quintais. 
Tabela 2 - Espécies cultivadas nos quintais da aldeia Wede'rã em 2008.

\begin{tabular}{lllll}
\hline Casa 1 & Casa 2 & Casa 3 & Casa 4 & Casa 5 \\
\hline Mandioca brava & Mandioca brava & Mandioca & Mandioca & Mandioca \\
Mandioca mesa & Mandioca mesa & Jatobá & Baru & Cará \\
Abacaxi & Caju & & Jatobá & \\
Mamão & Manga & & Timbó & \\
Urucum & Limão & & Pequi & \\
Pequi & Laranja & & Caju & \\
Buriti & Buriti & & Laranja & \\
& Pequi & & Abacaxi & \\
& Baru & & Limão & \\
& Coco & & & \\
\hline
\end{tabular}

Tabela 3 - Espécies cultivadas nos quintais da aldeia Wede'rã em 2009.

\begin{tabular}{lllll}
\hline Casa 1 & Casa 2 & Casa 3 & Casa 4 & Casa 5 \\
\hline Abacaxi & Abacaxi & Abacaxi & Abacaxi & Abacaxi \\
Caju & Abóbora & Caju & Caju & Caju \\
Coco & Baru & Coco & Abóbora & Amendoim \\
Palmeira nativa & Batata-doce & Erva-cidreira & Baru & Baru \\
Jatobá & Cabaça & Laranja & Cará & Cará \\
Laranja & Caju & Macaúba & Erva-cidreira & Abóbora sp.1 \\
Mandioca brava & Cará xavante & Mandioca brava & Laranja & Abóbora sp. 2 \\
Manga & Coco & Melancia & Limão & Coco \\
Melancia & Laranja & Pequi & Mandioca brava & Mooni höiré \\
Nodzö'á & Limão & Urucum & Manga & Erva-cidreira \\
Nodzöpré & Macaúba & & Melancia & Feijão xavante \\
Urucum & Mandioca brava & & Pequi & Laranja \\
Pequi & Manga & & Babaçu & Macaúba \\
& Melancia & & & Mandioca brava \\
& Pequi & & & Manga \\
& Urucum & & & Melancia \\
& Medicinal & & Algodãoxavante \\
& & & & Milho xavante \\
\hline
\end{tabular}


Tabela 4 - Espécies cultivadas nos quintais da aldeia Wede'rã em 2010.

\begin{tabular}{|c|c|c|c|c|c|c|}
\hline Casa 1 & Casa 2 & Casa 3 & Casa 4 & Casa 5 & Casa 6 & Casa 7 \\
\hline Abacaxi & Manga & Caju & Baru & Abóbora & Macaúba & Abóbora \\
\hline Abóbora & Caju & Abacaxi & Abóbora & Laranja & Baru & Pequi \\
\hline Caju & Abacaxi & Abóbora & Abacaxi & Melancia & Abare'ture & Macaúba \\
\hline Pequi & Macaúba & Urucum & Melancia & Abare'ture & $\begin{array}{l}\text { Algodão } \\
\text { xavante }\end{array}$ & $\begin{array}{l}\text { Mandioca } \\
\text { brava }\end{array}$ \\
\hline Melancia & Urucum & Macaúba & Limão & Tomonti & Melancia & Abacaxi \\
\hline Macaúba & Laranja & Abare'ture & Abare'ture & Zoroin'ró & $\begin{array}{l}\text { Mandioca } \\
\text { brava }\end{array}$ & $\begin{array}{l}\text { Mandioca } \\
\text { mesa }\end{array}$ \\
\hline $\begin{array}{l}\text { Mandioca } \\
\text { brava } \\
\text { Urucum }\end{array}$ & $\begin{array}{l}\text { Mandioca } \\
\text { brava } \\
\text { Limão }\end{array}$ & $\begin{array}{l}\text { Algodão } \\
\text { xavante } \\
\text { Melancia }\end{array}$ & $\begin{array}{l}\text { Mandioca } \\
\text { brava } \\
\text { Macaúba }\end{array}$ & $\begin{array}{l}\text { Mandioca } \\
\text { brava }\end{array}$ & $\begin{array}{l}\text { Erva- } \\
\text { cidreira } \\
\text { Zoroin'ró }\end{array}$ & $\begin{array}{l}\text { Algodão } \\
\text { xavante } \\
\text { Caju }\end{array}$ \\
\hline Jatobá & $\begin{array}{l}\text { Erva- } \\
\text { cidreira }\end{array}$ & $\begin{array}{l}\text { Mandioca } \\
\text { brava }\end{array}$ & Jatobá & & Abóbora & Laranja \\
\hline $\begin{array}{l}\text { Laranja } \\
\text { Manga } \\
\text { Zoroin'ró }\end{array}$ & $\begin{array}{l}\text { Cana } \\
\text { Coco } \\
\text { Algodão } \\
\text { Abóbora } \\
\text { Mamão } \\
\text { Pequi } \\
\text { Melancia } \\
\text { Baru } \\
\text { Gengibre } \\
\text { Banana } \\
\text { Abare'ture } \\
\text { Tomonti }\end{array}$ & $\begin{array}{l}\text { Laranja } \\
\text { Pequi }\end{array}$ & $\begin{array}{l}\text { Laranja } \\
\text { Manga }\end{array}$ & & $\begin{array}{l}\text { Feijão } \\
\text { Coco }\end{array}$ & $\begin{array}{l}\text { Abare'ture } \\
\text { Manga } \\
\text { Melancia }\end{array}$ \\
\hline
\end{tabular}

Esse incremento de espécies cultivadas nos quintais deu-se principalmente pelo plantio de frutíferas perenes, quando antes os cultivos eram realizados nas roças e, após a fixação das aldeias, é que houve a produção alimentícia nesses locais.

Os quintais tornaram-se importantes para produção agrícola e possuem alta diversidade de espécies, tanto nativas do cerrado, quanto exóticas. Adams et al. (2005) relataram a importância destas entre populações ribeirinhas do Amazonas, em que a maior parte dos cultivos era para alimentação e havia pouco cultivo de medicinais.

Os quintais apresentam-se como fonte complementar de alimentos. A comunidade considera que essas áreas não são boas para o cultivo de roças, como milho e feijão. As frutíferas, por não exigirem muitos cuidados, são compatíveis com o pouco tempo dedicado para essa atividade, mesmo a comunidade atualmente dependendo mais dos produtos da agricultura para sua subsistência. Silva (1983) chamou atenção, na década de 1980, para o fato 
de que os xavantes estavam se tornando agricultores, e esse evento poderia fazer com que eles gastassem mais tempo com essa atividade, e menos tempo teriam para a vida social.

Num primeiro momento, a agricultura que se intensificou entre os xavantes, foi a de cultivos mecanizados, havendo maior tempo de trabalho nessa atividade. De fato, na TI Pimentel Barbosa, nas décadas de 1970 e 1980, foi realizado cultivo de arroz mecanizado, havendo participação da comunidade. Esse projeto encerrou-se nos anos 1980. Porém, de 2005 a 2008, a Associação Cana Rica desenvolveu esse mesmo modelo de projeto, numa concepção na qual a maior parte das etapas agrícolas era realizada por não-índios; a comunidade de Wedé rã participava apenas nas etapas da capina e colheita.

Atualmente, com mais produtos da agricultura, principalmente o arroz, a coleta não é praticada com frequência. As jovens não conhecem tantas espécies de plantas do cerrado, sua localização e época de produção. Essa situação é agravada pelo fim da mobilidade espacial. A maior exploração do território permanece apenas com os homens na prática de caça.

Para Ferreira (2006), a produção do alimento se estabelece como relação moral dos homens com a natureza, onde a terra de trabalho é construída pelos saberes. A organização da produção leva em conta os ciclos próprios da natureza, a partir do qual se constroem as técnicas mais adequadas e os processos de trabalho. Em suas práticas produtivas, essas comunidades expressam sua leitura do ambiente, desenvolvida num movimento de relações empíricas e cotidianas com o meio, na construção de seu modo de vida. A leitura que fazem do seu espaço ecológico remete aos usos que elas aí praticam, diretamente relacionados à reprodução da sua vida material e simbólica.

\section{Considerações finais}

A partir do fim da mobilidade espacial pelo território entre os Xavantes de Pimentel Barbosa, houve incremento da agricultura e do plantio nos quintais, com redução da coleta de frutos nativos e seu uso na alimentação. Há conhecimento das espécies e das diferentes formas de uso, porém isso não garante seu consumo com frequência, devido principalmente ao consumo de arroz, que é produzido mecanicamente através de projetos desenvolvidos por agricultores da região e da FUNAI. 


\section{Referências}

ADAMS, Cristina; MURRIETA, Rui Sérgio; SANCHES, Rosely Alvim. Agricultura e alimentação em populações ribeirinhas das várzeas do Amazonas: novas perspectivas. Ambiente \& Sociedade, Campinas, v. 8, n. 1, p. 65-86, 2005.

ALTIERI, Miguel; NICHOLLS, Clara. Agroecología: teoría y práctica para una agricultura sustentable. México: Programa de las Naciones Unidas para el Medio Ambiente, 2000.

BADINTER, Elisabeth. Um é o outro: relaç̃es entre homens e mulheres. 4. ed. Rio de Janeiro: Nova Fronteira, 1986.

BARBOSA, Hélio Batista; CRAVEIRO, Silvia (Org.). Na trilha da cidadania: iniciativas para a promoção dos direitos das comunidades indígenas. São Paulo: Programa Gestão Pública e Cidadania, 2004.

FERREIRA, Simone Raquel Batista. Campesinidade e território quilombola no Norte do Espírito Santo. GEOgrafia, Rio de Janeiro, n. 16, p. 57-82, 2006.

FUNDAÇÃO NACIONAL DO ÍNDIO - FUNAI. [s.d.]. Disponível em: <www.funai. gov.br>. Acesso em: 10 fev. 2007.

INSTITUTO SOCIOAMBIENTAL - ISA. Transformando o arco do desmatamento no arco do desenvolvimento sustentável: uma proposta de ações emergenciais, [s.d.]. [online]. Disponível em: <http://www.socioambiental.org/esp/novogov/proposta.htm>. Acesso em: 12 dez. 2009.

LEEUWENBERG, Frans; SALIMON, Mario. Para sempre A'uwê: os xavante na balança das civilizações. Brasília: Artwork, 1999.

LEITE, Maurício Soares. Transformação e persistência: antropologia da alimentação e nutrição em uma sociedade indígena amazônica. Rio de Janeiro: Fiocruz, 2007.

MAYBURY-LEWIS, David. A sociedade xavante. Rio de Janeiro: Francisco Alves, 1984.

MENEZES, Cláudia. Os xavante e o movimento de fronteira no leste matogrossense. Revista de Antropologia, São Paulo, v. 25, p. 63-87, 1982.

SAHLINS, Marshal. A primeira sociedade da afluência. In: CARVALHO, Edgar (Org.). Antropologia econômica. São Paulo: Ciências Humanas, 1978. p. 6-43.

SERPA, P. Povos indígenas do Brasil. Instituto Socioambiental, 2001. [online]. Disponível em: <www.socioambiental.org.br>. Acesso em: 22 jan. 2010.

SILVA, Aracy Lopes da. Xavante: casa - aldeia - chão - terra - vida. In: CAIUBY, Sylvia Novaes (Org.). Habitações indígenas. São Paulo: Nobel, 1983.

VIERTLER, Renate Brigite. Ecologia cultural: uma antropologia da mudança. São Paulo: Ática, 1988.

WOORTMANN, Ellen Fensterseifer. O ambiente e a mulher: o caso do litoral do Rio Grande do Norte, Brasil. In: WOORTMANN, Ellen Fensterseifer. Respeito à diferença: uma introdução à antropologia. Brasília: Fundação Universidade de Brasília, 1999.

\section{Recebido em 4 de fevereiro de 2014}

Aprovado para publicação em 10 de junho de 2015 